\title{
Stroke Research in the Modern Era: Images versus Dogmas
}

\author{
Jean-Claude Baron \\ Department of Neurology and Stroke Unit, University of Cambridge, Cambridge, UK
}

\section{Key Words}

Stroke - Penumbra - Misery perfusion · Diaschisis •

Plasticity $\cdot$ Brain imaging

\begin{abstract}
Recovery of function following ischaemic stroke is a fascinating clinical observation. It comprises several modes, e.g. spectacular recovery in a matter of hours or days and gradual recovery over months or even years. That a non-functioning neural system can regain its function, even partially so, is challenging because of the obvious therapeutic implications. Until the mid-70s, however, dogmas largely prevailed which underpinned the then nihilistic approach to stroke patients. Proving these dogmas wrong has been a major achievement of modern stroke research. Thanks particularly to physiological imaging, key observations from the basic neurosciences have translated into the clinical realm in ways immediately understandable to the clinician, allowing the emergence of pathophysiology-based management.
\end{abstract}

Copyright $(C) 2005$ S. Karger AG, Basel

\section{Introduction}

Among the most fascinating observations in clinical neurology is recovery of function following stroke. Particularly spectacular is the recovery from extensive hemispheric syndrome that can be complete in a matter of hours or days, as it indicates that once inactive neurones have regained their normal function. Equally intriguing is the gradual and often considerable recovery that can proceed over weeks, months and occasionally years after stroke, suggesting compensatory processes develop to circumvent the established damage. Yet, the extent of recovery may vary despite a similar lesion, which suggests individual factors can modulate these processes. Understanding the neural substrates of recovery from the acute to the chronic stage has considerable implications for management, with the prospect to improve final outcome. However, long-held dogmas and misconceptions prevailed until recently, which led to a nihilistic and empirical approach to stroke management. Proving them wrong has been the main achievement of modern stroke research.

Critical in this progress has been physiological brain imaging using PET, SPECT, CT or MR. These techniques provide maps of physiological variables key to the ischaemic process such as circulation time, tissue perfusion, oxidative and anaerobic metabolism and water diffusion. They also allow us to map resting synaptic activity and activation of neural networks during behaviour, opening a unique window on reorganisation, plasticity and secondary degeneration. Imaging the brain directly in stroke victims has permitted fundamental observations from the basic neurosciences to translate into the clinical realm in ways immediately understandable to the clinician. Regarding acute stroke, for instance, it became for the first time possible to address such key questions as: What is the target of therapy? What is the most appropriate therapy? Which patients are likely to benefit,

\section{KARGER \\ Fax +4161306 1234 E-Mail karger@karger.ch} www.karger.com
(C) 2005 S. Karger AG, Basel $1015-9770 / 05 / 0203-0154 \$ 22.00 / 0$

Accessible online at: www.karger.com/ced
Prof. Jean-Claude Baron

Department of Clinical Neurosciences

University of Cambridge, Addenbrooke's Hospital, Box 83

Cambridge CB2 2QQ (UK)

Tel. +44 1223 217806, Fax +44 1223 217909, E-Mail jcb54@cam.ac.uk 
and which likely to be harmed? For how long might therapy remain beneficial? In the last 25 years, physiological imaging has revolutionized not only stroke science, but also the clinical approach to stroke, with pathophysiology-based management now becoming part of daily practice.

This article will focus on my contributions to these advances, successively addressing four topics that are key to stroke pathophysiology.

\section{Misery Perfusion}

Until the late 70s, TIAs were thought to be always embolic, i.e. haemodynamic factors were believed to play no part even when the TIA occurred distal to a previously documented internal carotid artery (ICA) occlusion. More generally, it was thought that ICA occlusion had no longlasting effect on brain haemodynamics - although some authorities like CM Fisher had dissenting views. Yet, extracranial-intracranial (EC-IC) bypass was being performed without clear rationale in large numbers of patients, even if not recently symptomatic.

In 1978, we initiated a PET study of cerebral blood flow (CBF) and oxygen metabolism using the steady-state oxygen-15 method before and after EC-IC bypass. We were hoping that PET would document any effects of surgery on these variables, and therefore would help us to identify in retrospect a logical indication to surgery, more specifically a pattern of changes suggestive of haemodynamic impairment. In most patients, however, there was no preoperative change in these variables (apart from any established infarct), and post-operatively no clear effect of the surgery. In late 1978, however, we studied a patient with ICA occlusion and continuing TIAs, some postural, despite optimal medical treatment. We observed a focally reduced $\mathrm{CBF}$ with increased oxygen extraction fraction (OEF) in the cortical watershed territory, and this focal flow-metabolism uncoupling resolved after successful ECIC bypass, together with the TIAs [1].

Notwithstanding some people who argued that this finding was an artifact of the steady-state method (which was still in its infancy), we searched the literature for a similar pathophysiological syndrome and were able to dig out a number of consistent findings [for details, see 1]. For instance, studies from the 50s had reported increased arterio-venous oxygen difference $\left(\mathrm{AVDO}_{2}\right)$ in situations of global hypoperfusion as well as during ICA clamping. This was due to unchanged $\mathrm{CMRO}_{2}$, as also reported in monkeys subjected to increased intracranial pressure [2].
In the $60 \mathrm{~s}$, measuring the $\mathrm{AVDO}_{2}$ had in fact become a classic way to indirectly estimate $\mathrm{CBF}$ in situations where the $\mathrm{CMRO}_{2}$ was assumed stable. As a focal event, dark blood had been observed in the cortical veins during middle cerebral artery (MCA) occlusion in monkeys, and focally preserved $\mathrm{CMRO}_{2}$ had been reported in the face of reduced $\mathrm{CBF}$ in subarachnoid haemorrhage. Reduced $\mathrm{CBF}$ and preserved $\mathrm{CMRO}_{2}$ had even been mentioned in a few patients with ICA occlusion, resolving after bypass. The hypothesis that the pattern of changes in our patient indeed reflected focal ischaemia was supported firstly by the fact that it predominated in the watershed, i.e. where the cerebral perfusion pressure was expected to be lowest, and secondly by the fact that it was alleviated by successful bypass, which is meant to increase the cerebral perfusion pressure. In reference to Lassen's 'luxury perfusion syndrome' (i.e. increased CBF with reduced $\mathrm{AVDO}_{2}$ ) [3], this physiological syndrome was coined 'misery perfusion' [1].

In parallel to the EC-IC bypass study, we had also initiated a study aiming to understand the pathophysiology of acute ischaemia. We also observed misery perfusion in that setting, especially in patients studied earliest after stroke onset (fig. 1). Previously, only the opposite type of focal flow-metabolism uncoupling, i.e. luxury perfusion, had been observed, but subacutely and within infarcted tissue [4]. The interpretation was that acute misery perfusion could represent "critical but potentially reversible ischaemia'. These findings were presented at the International CBF Conference in June 1979 [5] and at an international workshop on computerized tomography in September 1979 [6], and published in full in 1981 [7]. Similar observations were reported by the Boston group [8,9].

Returning to the index EC-IC bypass patient, the paper was presented at the Salzburg Conference on Cerebrovascular Disease in September 1980 [10], and the full article published in 1981 following a lengthy review process [1]. We subsequently replicated the findings in additional similar cases [11], and also documented misery perfusion distal to MCA stem disease [12].

Misery perfusion for the first time provided a rational basis for EC-IC bypass surgery in symptomatic ICA occlusion or intracranial stenosis. Because it was found in only a minority of potential surgical candidates [10, 12], the number of operations dramatically decreased in Paris in the early $80 \mathrm{~s}$, long before the negative results of the EC-IC randomized controlled trial (RCT) were published [13]. Although the design of this trial was criticized for not having used haemodynamic failure as an entry criterion, the controversy calmed down for several years after 

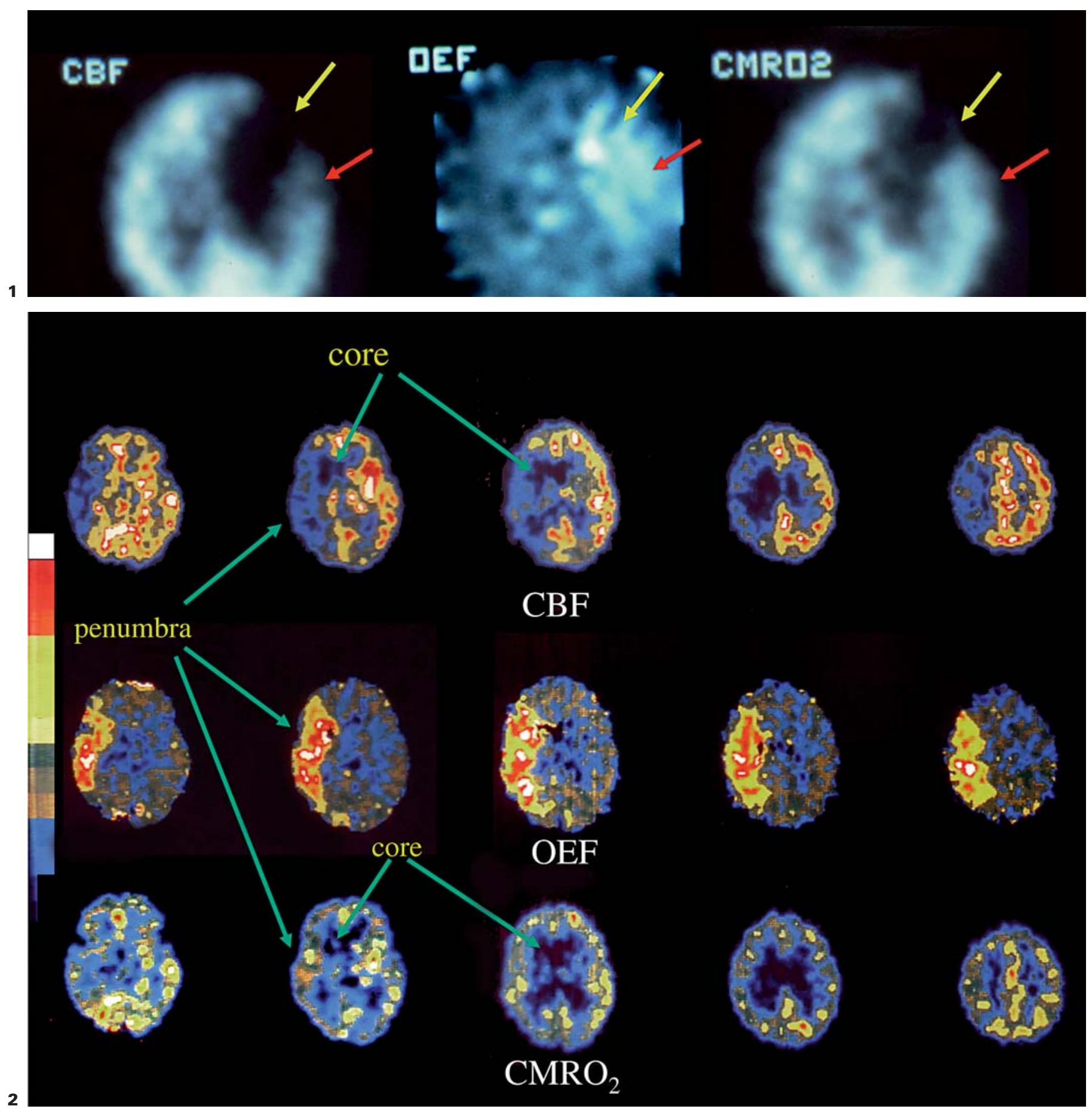

Fig. 1. Early demonstration of acute misery perfusion in a patient studied with PET $30 \mathrm{~h}$ after left carotid territory stroke. Images were acquired in the late 70s using the ECAT II single-slice PET device (resolution: $20 \times 20 \times 20 \mathrm{~mm}, \mathrm{x}, \mathrm{y}, \mathrm{z}$ ). There is reduced CBF and high OEF in the left anterior MCA territory, characterizing misery perfusion. Note however that the $\mathrm{CMRO}_{2}$ further defines two distinct areas within cortical misery perfusion: posteriorly, the $\mathrm{CMRO}_{2}$ is well preserved (red arrows), i.e. the tissue is viable, which could represent penumbra or oligemia or both; ante- riorly, however, the $\mathrm{CMRO}_{2}$ is close to zero (yellow arrows), which indicates irreversibly damaged tissue where perfusion is lower than metabolic needs. This serves to illustrate the point that misery perfusion/high OEF is necessary but not sufficient to identify the penumbra (see text for further discussion on this).

Fig. 2. Acute misery perfusion in a patient with MCA territory stroke studied with high-resolution multi-slice PET $12 \mathrm{~h}$ after clinical onset. Five transaxial cuts are represented. The 16-level pseudocolor scale (shown on the right) ranges from 0 (black) to 
the St. Louis group published two retrospective nonrandomized studies $[14,15]$ that concluded that misery perfusion was a good predictor neither of stroke in non-operated patients, nor of good outcome in operated ones. This view was subsequently corrected by four prospective studies - including one from St Louis - consistently showing misery perfusion (or severely impaired vasodilatory reserve as a surrogate) distal to symptomatic ICA disease to be a highly significant predictor of ipsilateral stroke, with an odds ratio around 8 [16-19]. Accordingly, two RCTs (including one NIH funded) recruiting only patients with documented misery perfusion or inadequate vasodilatory reserve are currently underway. It must be noted, however, that in such patients misery perfusion documents chronically impaired cerebrovascular autoregulation, making these patients at particularly high risk of postoperative complications. Knowledge of this situation should dictate special caution in the post-operative management of blood pressure, and similarly the BP should not be allowed to drop excessively in non-operated patients, for instance from antihypertensive agents.

\section{Mapping the Penumbra}

Until the mid 70s, it was believed that following a stroke neurones would die within minutes, in analogy with the situation in cardiac arrest. This dogma underpinned the then prevailing nihilistic approach to stroke. In the mid-70s, however, Hossmann [20] documented that brain death is evitable after cardiac arrest, and almost simultaneously Symon and colleagues [21-23] challenged the related dogma regarding focal stroke. These authors showed that occlusion of the MCA does not result in complete cessation of flow but instead in a gradient of CBF decrease, within which they characterized a peripheral area of cortex where CBF is below $\sim 20 \mathrm{ml} / 100 \mathrm{~g} / \mathrm{min}$, neuronal activity is lost on electrocorticography, but the cells are not irreversibly depolarized. If reperfused, this zone could regain its function and escape infarction, con-

$60 \mathrm{ml} / 100 \mathrm{~g} / \mathrm{min}, 1.00$ and $4.5 \mathrm{ml} / 100 \mathrm{~g} / \mathrm{min}$ (white) for CBF, OEF and $\mathrm{CMRO}_{2}$, respectively. There is strikingly reduced CBF (with values consistently $<20 \mathrm{ml} / 100 \mathrm{~g} / \mathrm{min})$ and high $\mathrm{OEF}(>0.70)$ in essentially the whole MCA territory, involving both the cortical and deep areas. Note however that the $\mathrm{CMRO}_{2}$ is markedly reduced (below the infarction threshold of $\sim 0.9 \mathrm{ml} / 100 \mathrm{~g} / \mathrm{min}$ ) in the striato-capsular area, suggesting irreversibly damaged tissue ('core'), whereas it is only mildly reduced in the cortical ribbon, consistent with penumbra (see text for details).

Stroke Research in the Modern Era trary to the ischaemic core with very low CBF and high extracellular $\mathrm{K}+$. The former region was coined the ischaemic penumbra.

The key issue of whether the same situation existed in the clinic, and if so for how long, was elusive as the techniques used by Symon in baboons were not applicable to man. PET looked promising because it permits to measure in the same locus both $\mathrm{CBF}$ and $\mathrm{CMRO}_{2}$, which is closely coupled with synaptic activity in large-scale neuronal ensembles. As stated above, misery perfusion had been observed in acute stroke in the late 70 s, and it was tantalizing to equate it with the viable penumbra. We however pointed out [7] that misery perfusion can affect tissue that exhibits close to zero $\mathrm{CBF}$ and $\mathrm{CMRO}_{2}$, and therefore is already severely and irreversibly damaged; in other words, high OEF does not equate with viable tissue (fig. 1). At the other end of the spectrum, the misery perfusion seen distal to ICA occlusion in patients with normal neurology [2] would not be eligible for penumbra but would represent oligemia, as defined by Lassen. Studies by others showed the limitations of trying to determine whether a region with misery perfusion is viable or nonviable by simply examining the values of $\mathrm{CBF}$, OEF and $\mathrm{CMRO}_{2}$ [24]. Additional variables, taking into account space, time and tissue outcome, were needed. In 1996, we proposed an operational model - widely adopted since - that translated into the following set of criteria: (a) the penumbra should exhibit both low CBF and high OEF; (b) the volume of (core + penumbra) should correlate with concomitant neurological deficit; (c) the penumbra has variable fate: it may undergo or escape infarction, and (d) clinical recovery should be proportional to the volume of penumbra that escapes infarction [25]. To test these criteria in a rigorous way, we designed a novel voxel-based approach to the analysis of multi-modality imaging data sets. Applied on a prospective series of patients studied within $18 \mathrm{~h}$ of onset, this approach documented tissue fulfilling all the above criteria, demonstrating for the first time the existence of the ischaemic penumbra in man [25].

We were the first to address the issue of core and penumbra thresholds in man. We first reported CBF and $\mathrm{CMRO}_{2}$ infarction thresholds for circular regions of interest at around 12 and $1.4 \mathrm{ml} / 100 \mathrm{~g} / \mathrm{min}$ [26]. In our series of patients studied in the 5- to 18-hour interval, we subsequently validated probabilistic $(\mathrm{p}<0.05)$ voxel-based infarction thresholds of $\sim 8.5$ and $0.9 \mathrm{ml} / 100 \mathrm{~g} / \mathrm{min}$ for $\mathrm{CBF}$ and $\mathrm{CMRO}_{2}$, respectively [27]; the CBV threshold $(1.64 \mathrm{ml} / 100 \mathrm{~g})$ failed short of statistical significance [27]. The penumbra threshold was more difficult to assess as 
it required dual $\mathrm{CBF}$ and $\mathrm{OEF}$ criteria; these were determined to be $<17 \mathrm{ml} / 100 \mathrm{~g} / \mathrm{min}$ and $>0.70$, respectively [25, 28] (fig. 2). Although our CBF infarction threshold applies only to the 5- to 18 -hour interval, the $\mathrm{CMRO}_{2}$ threshold probably is time-independent, so mapping the penumbra and core regardless of time since onset is feasible.

We were the first to assess the potential use of ${ }^{11} \mathrm{C}$-labelled flumazenil and PK11,195, ligands of the central and peripheral benzodiazepine receptors respectively, as surrogate markers of neuronal loss in vivo, following MCA occlusion in the baboon [29]. We found that ${ }^{11} \mathrm{C}$ flumazenil was extremely sensitive, being markedly reduced as early as $24 \mathrm{~h}$ after stroke in the evolving infarct, while the increased ${ }^{11} \mathrm{C}-\mathrm{PK} 11,195$ uptake (reflecting microglial activation) was both delayed to the second week and poorly demarcated. Building on this work, Heiss et al. [30] proposed to combine ${ }^{11} \mathrm{C}$-flumazenil and $\mathrm{CBF}$ to map the core and penumbra in hyperacute stroke.

For treatment purposes, the duration of the penumbra was also important to determine. Studies in awake monkeys had indicated that very little penumbra still existed after $3 \mathrm{~h}$ of MCA occlusion [31], and studies in the cat and rat suggested even shorter intervals. Although this seminal study in monkeys was critical in underpinning the highly successful NINDS RCT of t-PA, the idea that the penumbra had the same time course in every case was a misconception. In our studies, we found substantial amounts of penumbra as late as $16 \mathrm{~h}$ after stroke onset in some patients, subsequently evolving to infarction [28]. In this sort of patients, therefore, there would be a rationale to contemplate treatment even that late after onset - though not necessarily t-PA. In other patients, however, no penumbra was present even very early after onset [32]. Subsequent studies using other imaging techniques confirmed our observations, as reviewed in reference [33]. This suggests that the pathophysiological process of infarction in man is extremely heterogeneous, considerably more so than in the laboratory animal, probably because the latter is chosen to be of uniform strain, gender and nutritional status; healthy and unmedicated; young and genetically pure.

In the same study [32], we showed that apart from those patients exhibiting substantial amounts of penumbra, about a third of patients studied within the 5- to 18hour interval had already reperfused (see below) while another third had extensive core involving most of the MCA territory. The latter two patterns could be observed as early as $5 \mathrm{~h}$ from onset [32]. In addition they were highly significant predictors of outcome, independent of admission clinical scores [34]. Thus, despite similar clinical presentation of MCA stroke and overlapping severity of deficit, the underlying physiological situation could radically differ from patient to patient. This, and the fact that the penumbra can be long-lived, prompted us to challenge the concept of a rigid and universal time-window for acute stroke therapy [35]. We proposed that the classic approach to stroke treatment, in which time from onset is the gold standard, was misconceived, and suggested instead that management should be based on individual pathophysiological diagnosis - although the earlier the treatment the better, so any significant delay should be avoided. Towards this, more accessible imaging techniques than PET were obviously needed. Importantly, however, the above three PET patterns were subsequently recovered with other imaging techniques, including MR-based DWI and PWI [36].

Because PET produces snapshots and would be very difficult and even unethical to repeat serially in acutely ill patients, one criterion defining the penumbra, namely its salvage by reperfusion, could not be easily established in man. This was important however since a widely prevalent concept at the time was that even though reperfusion could save the penumbra, it would result in aggravated cell damage, inflammation, capillary clogging, vasogenic edema and haemorrhage from rupture of damaged vasculature - so-called 'reperfusion injury'. To address this and other issues, we were the first to successfully set up the methodology allowing serial quantitative PET scanning in the primate subjected to permanent or temporary MCA occlusion [37]. Applying this methodology, we documented that reperfusion was able to reverse misery perfusion and salvage part of the affected tissue, which resulted in vastly reduced infarct volumes as measured stereologically post-mortem [38-41]. In this model, recruitment of the cortical penumbra into the initially deep-seated core was a slow process evolving over at least

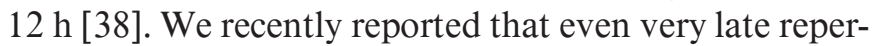
fusion (20-hour occlusion) caused no harm in this baboon model, i.e. infarct volume was no larger than with permanent occlusion, animals made a good recovery, and no haemorrhage was seen pathologically [42].

Studies in patients concurred with this view. In about a third of patients studied in the 5- to 18-hour interval after onset of MCA territory stroke, we documented the presence of high $\mathrm{CBF}$ with low OEF in the affected territory, i.e. the hallmark of reperfusion of the ischaemic brain. Yet, in almost $100 \%$ of these patients, the hyperperfused tissue was eventually structurally intact, while clinical recovery was always excellent [43]. Together with 
the above corpus of findings in the baboon, this suggested that early reperfusion is beneficial clinically and probably harmless at the cellular level [44]. It also settled the longheld controversy about viability of tissue with low $\mathrm{OEF}$ [7-9, 24].

Applying the above concepts to other imaging techniques, we showed that although perfusion SPECT yielded globally similar findings as PET with respect to patient categorization and prognostication, this was at the cost of reduced accuracy due to lack of both quantification of $\mathrm{CBF}$ and metabolic information [45-47]. This, added to the time needed to complete a SPECT study, made this approach not very promising.

In Cambridge, our group currently uses $\mathrm{CT}$ perfusion to help select candidates for thrombolysis, and we find this technique to be quite useful. In 2 patients in whom time of onset was unknown but CT perfusion showed extensive hypoperfusion vastly exceeding the core, we were able to implement thrombolysis, which resulted in recanalization and spectacular recovery [48]. Thus, perfusion imaging appears an excellent substitute for the ticking clock when time of stroke onset is unknown such as in awakening deficit.

MR-based DWI and PWI is currently the most widely used imaging method to assess patients eligible for thrombolysis. In routine clinical implementation, the penumbra is thought to equate with the 'mismatch' area, i.e. the hypoperfused tissue not showing DWI hyperintensity. By combining PET and MR in acute patients, we recently documented that the DWI lesion in fact contains not only core but also penumbra, and can have other underlying flow-perfusion patterns than misery perfusion $[49,50]$. This suggests that interpretation of acute stroke MR is not straightforward, in agreement with animal and human data showing that the DWI lesion can be permanently reversed by reperfusion [51]. One clinical implication would be that patients with matched DWI/PWI lesions might still have salvageable tissue. Despite these caveats, MR remains the most useful method to assess the acute stroke patient, as it combines both exquisite diagnostic and key physiologic information. Accordingly, Ribo et al. [52] recently documented the successful use of stroke MRI in selecting patients for i.v. t-PA in the 3- to 6-hour window.

Although reperfusing the penumbra before it is infarcted is undoubtedly beneficial, whether the salvaged penumbra is genuinely healthy is an intriguing issue. It has been widely assumed that the non-infarcted penumbra immediately regains its function. However, this may not always be so, especially when the occlusion has lasted several hours. This is an important issue to address as any damage to the penumbra might delay or hamper clinical recovery. Our data [25] suggested that the spontaneously surviving penumbra more strongly sustained late (2month) than early (7-day) clinical recovery, as if the tissue did not recover full function immediately but rather provided the peri-infarct neuronal architecture necessary for long-term plasticity (see the section 'Cortical Map Changes and Network Reorganisation' below for further discussion on this). Consistent with this view, we reported that when patients were restudied 2-3 weeks later, the $\mathrm{CMRO}_{2}$ in the surviving penumbra was substantially reduced (although much less so than in infarcted tissue), suggesting underlying cell damage [53]. Interest in the fate of the reperfused penumbra has recently resurfaced following the observation in both the animal and man that the acute DWI lesion can be reversed after reperfusion but may secondarily reappear, in all or in part, despite effective and permanent reperfusion $[54,55]$. In rat, cat and primate temporary MCA occlusion models, selective neuronal loss and microglial activation are consistently found in peri-infarct areas [55]. Back in 1983, Lassen [56] formulated the hypothesis that 'incomplete infarction' possibly affected the peri-infarct area after MCA stroke. Despite some supportive data $[57,58]$, whether these cellular processes prevail in the reperfused penumbra in man and hamper recovery remains to be established. We have preliminary PET data in the rat to suggest that the combined use of ${ }^{11} \mathrm{C}$-labeled flumazenil and PK11,195 might go a long way in answering this question [59]. Was prevention of these cellular events shown to further enhance outcome, important new targets for therapy would have been identified.

\section{Diaschisis}

For decades, early functional recovery after stroke was readily explained at the bedside by resolution of a widespread 'neural shock' - an analogy to the 'spinal shock' that accompanies acute cord lesions. This concept, coined 'diaschisis' by von Monakow at the turn of the 20th century [reviewed in 60], implied that because function is distributed over widespread neural networks, acute damage at one node would result in synaptic depression in other spatially distant but connected nodes, which would not only account for the acute clinical deficit but also readily explain early recovery through resolution of the 'shock'. According to this concept, recovery was therefore a passive process - further underpinning therapeutic ni- 
hilism. Diaschisis from supratentorial stroke was thought to mainly involve the ipsilateral and contralateral cerebral hemispheres, especially the mirror regions transcallosally. To prove diaschisis was however challenging with available techniques - aside from the irrelevant situation of mass effect resulting in global hemispheric dysfunction and drowsiness. Using CBF as a surrogate for synaptic activity was clearly inadequate in the acute stroke situation, with drugs, age and prior risk factors as further confounds. No direct demonstration of diaschisis was therefore available until the advent of PET. Because dominated by synaptic activity, resting-state $\mathrm{CMRO}_{2}$ and $\mathrm{CMR}$ glucose measurements are ideally suited to address this issue, although some of the above confounds still apply. Using these tools, we discovered a heretofore completely unsuspected sort of remote synaptic depression affecting the cerebellar hemisphere contralateral to supratentorial strokes, which we coined 'crossed cerebellar diaschisis' (CCD). CCD was readily explained by disruption of the crossed cortico-cerebellar pathways, so fulfilled the disconnection criterion for diaschisis. This finding was presented in Boston in early September 1980, first at the C Miller Fisher Day on the occasion of his retirement, and a few days later at the American Neurological Association 105th annual meeting [61]. This undisputable demonstration of diaschisis opened the way to numerous other studies on this intriguing phenomenon. CCD was quickly confirmed by the London group [62], while Kuhl et al. [63] reported cortical hypometabolism after striato-capsular haemorrhage. Regarding the role of CCD in functional recovery, however, we subsequently showed that although it could be observed immediately after the stroke, consistent with the concept of diaschisis $[64,65]$, it tended not to resolve despite concomitant clinical recovery $[65,66]$, while its intensity in the chronic stage was directly related to infarct size. Altogether, therefore, CCD appeared to play no substantial part in functional recovery.

We also addressed the issue of ipsilateral and contralateral hemispheric diaschisis. In baboons subjected to permanent MCA occlusion, we found no immediate reduction in contralesional $\mathrm{CMRO}_{2}$, but instead a global metabolic depression building up over 2 weeks, inconsistent with diaschisis $[37,38]$. In patients, we also found that the $\mathrm{CMRO}_{2}$ decreased significantly from the acute (day 1 ) to the subacute ( day 20) stage in both the unaffected and the affected but non-infarcted hemisphere, despite concomitant clinical recovery $[67,68]$. Furthermore the $\mathrm{CMRO}_{2}$ in the subacute stage correlated with infarct size. These findings suggested that these remote metabolic effects only reflect widespread nerve terminal de- generation secondary to the infarc $[37,38]$, an epiphenomenon well described in animal stroke models.

Overall, therefore, survival of the penumbra, rather than resolution of diaschisis, appears as the major mechanism underlying early recovery after stroke, which carries clear therapeutic implications.

A vastly different sort of remote metabolic depression involves the cortex ipsilateral to thalamic stroke [69]. This so-called 'thalamo-cortical diaschisis' (TCD) is almost invariably observed even in small thalamic infarcts when language impairment or neglect are present $[69,70]$, and is prominent in bilateral paramedian infarcts resulting in dementia [71]. We proposed that this phenomenon reflects disruption of the diffuse activating thalamo-cortical pathway. Conversely, no significant cortical metabolic depression was present in patients with sensorimotor deficit but intact cognition from posterolateral thalamic stroke [72]. The relationship between TCD and cognitive impairment was further supported by studies of Vim thalamotomy, which documented that post-operatively the degree of language or visuo-spatial impairment is proportional to the severity of TCD [70]. After thalamic stroke, both cortical metabolism and cognitive deficits tend to slowly improve in parallel $[69,70]$, suggesting that slow alleviation of TCD via, e.g., sprouting of remaining thalamo-cortical fibers might partly subtend neuropsychological recovery. Were this to be formally confirmed, TCD would stand as a particular case among the remote metabolic effects of stroke.

\section{Cortical Map Changes and Network Reorganisation}

Although recovery from hemiplegia in children was readily explained by plasticity such as the taking over by the contralesional uncrossed cortico-spinal tract, plasticity and neural network reorganisation were thought not to operate in the adult brain [73]. This dogma had important consequences since it implied that the only possible way for stroke patients to improve their functional abilities was by adopting new behavioural strategies, getting around rather than relearning the lost function. In the $80 \mathrm{~s}$ and early 90s, however, Merzenich et al. [74] for the somatosensory cortex, and subsequently Nudo et al. for the primary motor cortex (M1) [75], documented the existence of plasticity in adult monkeys. However, studying brain plasticity directly in humans was virtually impossible until the advent of functional imaging. 
Functional imaging with PET during execution of motor tasks with the affected hand has provided clear evidence of reorganisation of cortical maps and neural networks after stroke in relation to recovery [76-78]. To clarify the role of these changes in functional recovery, however, longitudinally studying patients as they recover is required. We implemented such a study in patients with subcortical stroke deafferenting M1, and found a dynamic expansion/displacement of ipsilesional M1 activation in the caudal and posterior direction, possibly reflecting the 'unmasking'/disinhibition of latent connections, or the recruitment of representations not normally devoted to this function (i.e. vicariance) [79, 80]. A second major finding was excessive bilateral M1 activation, which tended to subside in parallel with recovery $[80,81]$. Specifically, the greater the activation of contralesional M1 in the chronic stage, the worse the recovery was, indicating that, contrary to intuitive logic, recruitment of contralesional M1 does not represent useful plasticity [82]. Quite to the contrary, recovery seemed to rely on predominant ipsilesional M1 involvement [80, 82]. Regarding cortical stroke affecting the M1 hand area, recent findings suggest dorsal shifts [77], replicating Nudo's findings in monkeys [75]. That the periinfarct area may be critical for recovery after cortical stroke would be entirely consistent with our above-described findings regarding the fate of the penumbra [25].

These observations documenting at least some degree of plasticity and redistribution of function after adult stroke have important implications. They indicate that it should be possible to manipulate plasticity to enhance recovery even in the chronic stage [76], by means of e.g., imaging-guided electromagnetic stimulation [83], specific rehabilitation paradigms [84] and/or pharmacologic agents [85]. Functional imaging might play a major role in this endeavour not only in defining which intervention is the most efficacious, but also who is likely to benefit from any particular intervention. With considerable implications for interventions however is how early does plasticity - adaptive or maladaptive - set in after stroke, which remains largely unknown.

\section{Conclusion}

Following generations of nihilism, improving the outcome of stroke victims has become a reality thanks to a better understanding of the underlying pathophysiological processes. Much remains to be done, however, and research still holds hopes to further enhance the outlook of stroke.

\section{Acknowledgements}

I am grateful to my mentors Marie-Germaine Bousser (Paris) and Robert H. Ackerman (Boston) and my spiritual fathers Niels A. Lassen (1927-1996) and C. Miller Fisher for inspiring my work, and to Dominique Comar (Orsay) for supporting my research in the early days of PET. I also wish to acknowledge the contributions of the following students and post-doctoral scientists (in chronological order): Philippe Lebrun-Grandié, MD; Marc Steinling, MD, PhD; Didier Rougemont, MD; Patrizia Pantano, MD; Yves Samson, MD; Roberta d'Antona, MD; Sabina Pappata, MD; Henri Cambon, MD; Giuliano Sette, MD; Michelle Levasseur, MD; Marco Fiorelli, MD, PhD and Hugues Chabriat, MD, PhD (Orsay); Gilles Marchal, MD, PhD; Marie-Christine Petit-Taboué, MD, PhD; Giuliano Sette, MD; Alan Young, PhD; Carlo Serrati, MD; Christian Dettmers, MD; Mauro Furlan, MD; Serge Iglesias, MD; Marie-Hélène Mahagne, MD, PhD; Cinzia Calautti MD and Cyrille Giffard, PhD (Caen), and Cinzia Calautti, MD; Joe Guadagno, MD; Isabelle Mayor MD and Jessica Hughes, MSc (Cambridge). This work would not have been possible without the contribution from a large number of collaborators whom I warmly thank collectively on this occasion. Finally, I am deeply indebted to my wife for her continuous support.

\section{References}

-1 Baron JC, Bousser MG, Rey A, Guillard A, Comar D, Castaigne P: Reversal of focal 'misery-perfusion syndrome' by extra-intracranial arterial bypass in hemodynamic cerebral ischemia. A case study with ${ }^{15} \mathrm{O}$ positron emission tomography. Stroke 1981;12:454-459.

-2 Grubb RL, Raichle ME, Phelps ME, Ratcheson RA: Effects of increased intracranial pressure on cerebral blood volume, blood flow, and oxygen utilization in monkeys. J Neurosurg 1975; 43:385-398.
Lassen NA: The luxury-perfusion syndrome and its possible relation to acute metabolic acidosis localised within the brain. Lancet 1966;ii:1113-1115.

4 Baron JC, Comar D, Bousser MG, et al: Etude tomographique, chez l'homme, du débit sanguin et de la consommation d'oxygène du cerveau par inhalation continue d'oxygène 15 . Résultats préliminaires dans les accidents ischémiques cérébraux. Rev Neurol (Paris) 1978; 134:545-556.
5 Baron JC, Comar D, Bousser MG, et al: Patterns of CBF and oxygen extraction fraction in hemispheric infarcts: a tomographic study with the ${ }^{15} \mathrm{O}$ inhalation technique. Acta Neurol Scand 1979;60(suppl 72):324-325.

6 Baron JC, Bousser MG, Comar D, Kellershon $\mathrm{C}$ : Human hemispheric infarction studied by positron emission tomography and the ${ }^{15} \mathrm{O}$ inhalation technique; in Caille JM, Salamon G (eds): Computerized Tomography. Berlin, Springer, 1980, pp 231-237. 
7 Baron JC, Bousser MG, Comar D, Soussaline F, Castaigne P: Noninvasive tomographic study of cerebral blood flow and oxygen metabolism in vivo. Potentials, limitations, and clinical applications in cerebral ischemic disorders. Eur Neurol 1981;20:273-284.

8 Ackerman RH, Alpert NM, Correia JA, et al: Correlations of PET scans with TCT scans and clinical course. Acta Neurol Scand 1979; 60(suppl 72):230-231.

$\checkmark 9$ Ackerman RH, Correia JA, Alpert NM, et al: Positron imaging in ischemic stroke disease using compounds labeled with oxygen 15 . Initial results of clinicophysiologic correlations. Arch Neurol 1981;38:537-543.

10 Baron JC, Guillard A, Bousser MG, Comar D, Castaigne P: Non-invasive tomographic imaging of cerebral blood flow and oxygen extraction fraction in superficial temporal artery to middle cerebral artery anastomosis; in Meyer $\mathrm{J}$ et al. (eds): Cerebral Vascular Disease. Amsterdam, Excerpta Medica, 1981, vol 12, pp 454-459.

11 Samson Y, Baron JC, Bousser MG, et al: Effects of extra-intracranial arterial bypass on cerebral blood flow and oxygen metabolism in humans. Stroke 1985;16:609-616.

12 Sgouropoulos P, Baron JC, Samson Y, Bousser MG, Comar D, Castaigne P: Sténoses et occlusions persistantes de l'artère cérébrale moyenne: conséquences hémodynamiques et métaboliques étudiées par tomographieà positons. Rev Neurol (Paris) 1985;141:698-705.

-13 Failure of extracranial-intracranial arterial bypass to reduce the risk of ischemic stroke. Results of an international randomized trial. The EC/IC Bypass Study Group. N Engl J Med 1985;313:1191-1200.

14 Powers WJ, Tempel LW, Grubb RL Jr: Influence of cerebral hemodynamics on stroke risk: one-year follow-up of 30 medically treated patients. Ann Neurol 1989;25:325-330.

15 Powers WJ, Grubb RL Jr, Raichle ME: Clinical results of extracranial-intracranial bypass surgery in patients with hemodynamic cerebrovascular disease. J Neurosurg 1989;70:61-67.

16 Grubb RL Jr, Derdeyn CP, Fritsch SM, et al: Importance of hemodynamic factors in the prognosis of symptomatic carotid occlusion. JAMA 1998;280:1055-1060.

-17 Yamauchi H, Fukuyama H, Nagahama Y, et al: Significance of increased oxygen extraction fraction in five-year prognosis of major cerebral arterial occlusive diseases. J Nucl Med 1999;40:1992-1998.

- 18 Kuroda S, Houkin K, Kamiyama H, Mitsumori K, Iwasaki Y, Abe H: Long-term prognosis of medically treated patients with internal carotid or middle cerebral artery occlusion: can acetazolamide test predict it? Stroke 2001;32: 2110-2116.

19 Ogasawara K, Ogawa A, Yoshimoto T: Cerebrovascular reactivity to acetazolamide and outcome in patients with symptomatic internal carotid or middle cerebral artery occlusion: a xenon-133 single-photon emission computed tomography study. Stroke 2002;33:18571862 .
20 Hossmann KA, Kleihues P: Reversibility of ischemic brain damage. Arch Neurol 1973;29: 375-384.

21 Symon L, Pasztor E, Branston NM: The distribution and density of reduced cerebral blood flow following acute middle cerebral artery occlusion: an experimental study by the technique of hydrogen clearance in baboons. Stroke 1974; 5:355-364.

22 Astrup J, Symon L, Branston NM, Lassen NA: Cortical evoked potential and extracellular $\mathrm{K}+$ and $\mathrm{H}+$ at critical levels of brain ischemia. Stroke 1977;8:51-57.

23 Branston NM, Symon L, Crockard HA: Recovery of the cortical evoked response following temporary middle cerebral artery occlusion in baboons: relation to local blood flow and $\mathrm{PO}_{2}$. Stroke 1976; 7:151-157.

24 Wise RJ, Bernardi S, Frackowiak RS, Legg NJ, Jones T: Serial observations on the pathophysiology of acute stroke. The transition from ischaemia to infarction as reflected in regional oxygen extraction. Brain 1983;106:197-222.

25 Furlan M, Marchal G, Viader F, Derlon JM, Baron JC: Spontaneous neurological recovery after stroke and the fate of the ischemic penumbra. Ann Neurol 1996;40:216-226.

26 Baron JC, Rougemont D, Bousser MG, Lebrun-Grandie P, Iba-Zizen MT, Chiras J: Local $\mathrm{CBF}$, oxygen extraction fraction (OEF), and CMRO2: prognostic value in recent supratentorial infarction in humans. J Cereb Blood Flow Metab 1983;3 (suppl 1):S1-S2.

27 Marchal G, Benali K, Iglesias S, Viader F, Derlon JM, Baron JC: Voxel-based mapping of irreversible ischaemic damage with PET in acute stroke. Brain 1999;122:2387-2400.

-28 Marchal G, Beaudouin V, Rioux P, et al: Prolonged persistence of substantial volumes of potentially viable brain tissue after stroke: a correlative PET-CT study with voxel-based data analysis. Stroke 1996;27:599-606.

29 Sette G, Baron JC, Young AR, et al: In vivo mapping of brain benzodiazepine receptor changes by positron emission tomography after focal ischemia in the anesthetized baboon. Stroke 1993;24:2046-2057; discussion 20572058.

30 Heiss WD, Kracht LW, Thiel A, Grond M, Pawlik G: Penumbral probability thresholds of cortical flumazenil binding and blood flow predicting tissue outcome in patients with cerebral ischaemia. Brain 2001;124:20-29.

31 Jones TH, Morawetz RB, Crowell RM, et al: Thresholds of focal cerebral ischemia in awake monkeys. J Neurosurg 1981;54:773-782.

32 Marchal G, Serrati C, Rioux P, et al: PET imaging of cerebral perfusion and oxygen consumption in acute ischaemic stroke: relation to outcome. Lancet 1993;341:925-927.

33 Donnan GA, Davis SM: Neuroimaging, the ischaemic penumbra, and selection of patients for acute stroke therapy. Lancet Neurol 2002; 1:417-424.
34 Marchal G, Rioux P, Serrati C, et al: Value of acute-stage positron emission tomography in predicting neurological outcome after ischemic stroke: further assessment. Stroke 1995;26: 524-525.

35 Baron JC, von Kummer R, del Zoppo GJ: Treatment of acute ischemic stroke. Challenging the concept of a rigid and universal time window. Stroke 1995;26:2219-2221.

36 Darby DG, Barber PA, Gerraty RP, et al: Pathophysiological topography of acute ischemia by combined diffusion-weighted and perfusion MRI. Stroke 1999;30:2043-2052.

37 Pappata S, Fiorelli M, Rommel T, et al: PET study of changes in local brain hemodynamics and oxygen metabolism after unilateral middle cerebral artery occlusion in baboons. J Cereb Blood Flow Metab 1993;13:416-424.

38 Touzani O, Young AR, Derlon JM, et al: Sequential studies of severely hypometabolic tissue volumes after permanent middle cerebral artery occlusion. A positron emission tomographic investigation in anesthetized baboons. Stroke 1995;26:2112-2119.

-39 Touzani O, Young AR, Derlon JM, Baron JC, MacKenzie ET: Progressive impairment of brain oxidative metabolism reversed by reperfusion following middle cerebral artery occlusion in anaesthetized baboons. Brain Res 1997; 767:17-25.

40 Young AR, Sette G, Touzani O, et al: Relationships between high oxygen extraction fraction in the acute stage and final infarction in reversible middle cerebral artery occlusion: an investigation in anesthetized baboons with positron emission tomography. J Cereb Blood Flow Metab 1996;16:1176-1188.

$\checkmark 41$ Young AR, Touzani O, Derlon JM, Sette G, MacKenzie ET, Baron JC: Early reperfusion in the anesthetized baboon reduces brain damage following middle cerebral artery occlusion: a quantitative analysis of infarction volume. Stroke 1997;28:632-637; discussion 637638.

-42 Giffard C, Young AR, Kerrouche N, Derlon JM, Baron JC: Outcome of acutely ischemic brain tissue in prolonged middle cerebral artery occlusion: a serial positron emission tomography investigation in the baboon. J Cereb Blood Flow Metab 2004;24:495-508.

43 Marchal G, Furlan M, Beaudouin V, et al: Early spontaneous hyperperfusion after stroke. A marker of favourable tissue outcome? Brain 1996;119:409-419.

44 Marchal G, Young AR, Baron JC: Early postischemic hyperperfusion: pathophysiologic insights from positron emission tomography. J Cereb Blood Flow Metab 1999; 19:467482.

45 Marchal G, Bouvard G, Iglesias S, et al: Predictive value of ${ }^{99 \mathrm{~m}} \mathrm{Tc}$-HMPAO-SPECT for neurological outcome/recovery at the acute stage of stroke. Cerebrovasc Dis 2000;10:8-17.

46 Mahagne MH, Darcourt J, Migneco O, et al: Early ${ }^{99 \mathrm{~m}}$ Tc-ethylcysteinate dimer brain SPECT patterns in the acute phase of stroke as predictors of neurological recovery. Cerebrovasc Dis 2000; 10:364-673. 
47 Mahagne MH, David O, Darcourt J, et al: Voxel-based mapping of cortical ischemic damage using Tc 99m L,L-ethyl cysteinate dimer SPECT in acute stroke. J Neuroimaging 2004; $14: 23-32$.

48 Hellier K, Hampton J, Higgins N, et al: CT perfusion helps decision making for thrombolysis when there is no clear time of onset. Cerebrovasc Dis 2005;19(suppl 2):71.

-49 Guadagno JV, Warburton EA, Aigbirhio FI, et al: Does the acute diffusion-weighted imaging lesion represent penumbra as well as core? A combined quantitative PET/MRI voxel-based study. J Cereb Blood Flow Metab 2004;24: 1249-1254.

>50 Guadagno JV, Warburton EA, Jones PS, et al: The diffusion-weighted lesion in acute stroke: heterogeneous patterns of flow/metabolism uncoupling as assessed by quantitative positron emission tomography. Cerebrovasc Dis 2005; 19:239-246.

-51 Kidwell CS, Saver JL, Mattiello J, et al: Thrombolytic reversal of acute human cerebral ischemic injury shown by diffusion/perfusion magnetic resonance imaging. Ann Neurol 2000;47: 462-469.

52 Ribo M, Molina CA, Rovira A, et al: Safety and efficacy of intravenous tissue plasminogen activator stroke treatment in the 3-6-h window using multimodal transcranial Doppler/MRI selection protocol. Stroke 2005;36:602-606.

53 Baron JC, Furlan M, Marchal G: The metabolic status of the ultimately noninfarcted ischemic penumbra: a positron emission tomography study in humans. Ann Neurol 1996;40: 498.

\$4 Kidwell CS, Saver JL, Starkman S, et al: Late secondary ischemic injury in patients receiving intraarterial thrombolysis. Ann Neurol 2002; 52:698-703.

55 Li F, Liu KF, Silva MD, et al: Transient and permanent resolution of ischemic lesions on diffusion-weighted imaging after brief periods of focal ischemia in rats: correlation with histopathology. Stroke 2000;31:946-954.

56 Lassen N, Olsen T, Hojgaard K, Skriver E: Incomplete infarction: a CT-negative irreversible ischemic brain lesion. J Cereb Blood Flow Metab 1983;3:S602-S603.

57 Nakagawara J, Sperling B, Lassen NA: Incomplete brain infarction of reperfused cortex may be quantitated with iomazenil. Stroke 1997;28: 124-132.

58 Gerhard A, Schwarz J, Myers R, Wise R, Banati RB: Evolution of microglial activation in patients after ischemic stroke: a [11C](R)PK11195 PET study. Neuroimage 2005;24: 591-595.
59 Hughes JL, Beech JS, Fryer TD, et al: Imaging post-ischaemic cellular changes using $11 \mathrm{C}$-flumazenil and microPET following temporal distal MCA occlusion in the spontaneously hypertensive rats (SHR). BRAIN 05 Conference, Amsterdam, June 6-9, 2005; Abstr BP96.

60 Feeney DM, Baron JC: Diaschisis. Stroke 1986;17:817-830.

61 Baron JC, Bousser MG, Comar D, Castaigne P: 'Crossed cerebellar diaschisis' in human supratentorial brain infarction. Trans Am Neurol Assoc 1980;105:459-461.

62 Lenzi GL, Frackowiak RS, Jones T: Cerebral oxygen metabolism and blood flow in human cerebral ischemic infarction. J Cereb Blood Flow Metab 1982;2:321-335.

63 Kuhl DE, Phelps ME, Kowell AP, Metter EJ, Selin C, Winter J: Effects of stroke on local cerebral metabolism and perfusion: mapping by emission computed tomography of $18 \mathrm{FDG}$ and 13NH3. Ann Neurol 1980;8:47-60.

64 Dettmers C, Hartmann A, Rommel T, Hartmann S, Pappata S, Baron JC: Contralateral cerebellar diaschisis $7 \mathrm{~h}$ after MCA-occlusion in primates. Neurol Res 1995; 17:109-112.

65 Serrati C, Marchal G, Rioux P, et al: Contralateral cerebellar hypometabolism: A predictor for stroke outcome? J Neurol Neurosurg Psychiatry 1994;57:174-179.

66 Pantano P, Baron JC, Samson Y, Bousser MG, Derouesne C, Comar D: Crossed cerebellar diaschisis. Further studies. Brain 1986;109:677694.

67 Iglesias S, Marchal G, Rioux P, et al: Do changes in oxygen metabolism in the unaffected cerebral hemisphere underlie early neurological recovery after stroke? A positron emission tomography study. Stroke 1996;27:1192-1199.

68 Iglesias S, Marchal G, Viader F, Baron JC: Delayed intrahemispheric remote hypometabolism. Correlations with early recovery after stroke. Cerebrovasc Dis 2000;10:391-402.

69 Baron JC, D'Antona R, Pantano P, Serdaru M, Samson Y, Bousser MG: Effects of thalamic stroke on energy metabolism of the cerebral cortex. A positron tomography study in man. Brain 1986;109:1243-1259.

70 Baron JC, Levasseur M, Mazoyer B, et al: Thalamocortical diaschisis: positron emission tomography in humans. J Neurol Neurosurg Psychiatry 1992;55:935-942.

71 Levasseur M, Baron JC, Sette G, et al: Brain energy metabolism in bilateral paramedian thalamic infarcts. A positron emission tomography study. Brain 1992;115:795-807.

72 Chabriat H, Levasseur M, Pappata S, Fiorelli M, Baron JC: Cortical energy metabolism in postero-lateral thalamic stroke. Acta Neurol Scand 1992;85:285-290.
3 Sereno MI: Neuroscience: plasticity and its limits. Nature 2005;435:288-289.

74 Merzenich MM, Kaas JH, Wall J, Nelson RJ, Sur M, Felleman D: Topographic reorganization of somatosensory cortical areas $3 \mathrm{~b}$ and 1 in adult monkeys following restricted deafferentation. Neuroscience 1983;8:33-55.

75 Nudo RJ, Wise BM, SiFuentes F, Milliken GW: Neural substrates for the effects of rehabilitative training on motor recovery after ischemic infarct. Science 1996;272:1791-1794.

76 Calautti C, Baron JC: Functional neuroimaging studies of motor recovery after stroke in adults: a review. Stroke 2003;34:1553-1566.

77 Jaillard A, Martin CD, Garambois K, Lebas JF, Hommel M: Vicarious function within the human primary motor cortex? A longitudinal fMRI stroke study. Brain 2005;128:11221138.

78 Chollet F, DiPiero V, Wise RJ, Brooks DJ, Dolan RJ, Frackowiak RS: The functional anatomy of motor recovery after stroke in humans: a study with positron emission tomography. Ann Neurol 1991;29:63-71.

79 Calautti C, Leroy F, Guincestre JY, Baron JC: Displacement of primary sensorimotor cortex activation after subcortical stroke: a longitudinal PET study with clinical correlation. Neuroimage 2003;19:1650-1654.

80 Calautti C, Leroy F, Guincestre JY, Baron JC: Dynamics of motor network overactivation after striatocapsular stroke: a longitudinal PET study using a fixed-performance paradigm. Stroke 2001;32:2534-2542.

81 Calautti C, Leroy F, Guincestre JY, Marie RM, Baron JC: Sequential activation brain mapping after subcortical stroke: changes in hemispheric balance and recovery. Neuroreport 2001; 12:3883-3886.

82 Calautti C, Naccarato M, Jones PS, et al: Motor performance in the stable phase of recovery after subcortical stroke is related to laterality of motor network activation. Stroke 2004;35: 285.

83 Cramer SC, Benson RR, Himes DM, et al: Use of functional MRI to guide decisions in a clinical stroke trial. Stroke 2005;36:e50-e52.

84 Carey JR, Kimberley TJ, Lewis SM, Auerbach EJ, Dorsey L, Rundquist P, Ugurbil K: Analysis of fMRI and finger tracking training in subjects with chronic stroke. Brain 2002; 125:773788.

85 Pariente J, Loubinoux I, Carel C, Albucher JF, Leger A, Manelfe C, Rascol O, Chollet F: Fluoxetine modulates motor performance and cerebral activation of patients recovering from stroke. Ann Neurol 2001;50:718-729. 